\title{
SOUTH AFRICAN COUNCIL FOR SCIENTIFIC AND INDUSTRIAL RESEARCH
}

\section{REPORT FOR 1954}

$\mathrm{T}$ HE ninth annual report of the South African Council for Scientific and Industrial Research, covering the year ended October 4, 1954*, is, as usual, bilingual but now printed in double column. The research unit set up last year within the National Chemical Research Laboratory to deal with the needs of the Department of Nutrition has now been given independent status, and the number of major national laboratories directly controlled by the Council is now six. The Council's staff exceeds seven hundred, including 158 research scientists; but reference is made to the acute shortage of experienced scientists and engineers, particularly at the management-level, both in government technical departments and in industry. Postgraduate bursaries were awarded to sixty men and women during the year to enable them to extend their research experience, and also sixteen senior bursaries to research workers in universities and scientific institutions. An increasing proportion of the Council's operating expenses is now being met from funds other than Parliamentary appropriations, while, of the $£ 90,000$ now available annually to the five industrial research institutes subsidized by the Council, more than half is received from the industries concerned. Two new medical research units were formed during the year-for dental and for heart research, respectively, the latter being chiefly on investigation of myocardial infarction and coronary arteries. At the end of the report are a list of research bursaries and assistantships awarded during the year and also a list of publications by the Council and its staff or bursars.

In the National Chemical Research Laboratory, where a shortage of technical assistants in relation to research staff severely handicaps most divisions of the work and more experienced staff for process development is also needed, studies of South African clays have continued and further fundamental data were obtained on the electrode potentials of chromium and iron in acid solution in the presence of a mercury electrode. A fundamental study of the mechanism of autoxidation of branched-chain hydrocarbons has been initiated, and the conditions established under which pure 5-methylnonane autoxidizes without extensive gross degradation. The Laboratory is also examining the catalysts to be used in the FischerTropsch process reactors and the products obtained with them. Considerable progress has been made in the desalting of brackish waters containing up to 10,000 p.p.m. of dissolved salts by electro-dialysis through ion-exchange membranes, and a pilot plant with a capacity of about 250 gallons per hour when desalting from 3,000 to 1,000 p.p.m. of sodium chloride has been operated day and night for several months to obtain design data for large-scale apparatus for gold mines in the Orange Free State to deal with brackish water. Problems involved in the purification of sewage effluents for re-use have again received priority, and operation of an experimental solar distillation unit has indicated that a unit of only $32 \mathrm{sq}$. $\mathrm{ft}$. pan area is sufficient to supply drinking

- South African Council for Scientific and Industrial Research, Ninth Annual Report, 1953-54. Pp. $x+142$. (From the Council, Pretoria, 1955.) water for a normal household in places where only saline water is available.

Work on wool and marine oils has continued vigorously, and the optical configuration of wool wax and brain $\alpha$-hydroxy acids was established by the synthesis of a series of $\mathrm{Ls}-\alpha$-hydroxy acids from Ls-malic acid. Continued study of sugar-cane cuticle wax has indicated that the main constituents are long-chain alcohols, and in view of the growing production of sisal in the Union the cuticular and wax coatings of the leaves of an Agave species have been studied. Fundamental structural studies are being made on the agar from Gracilaria confervoides; the mechanism of polymerization of certain natural fats has been further studied and the structure of methyl linoleate dimer investigated by a dehydrogenationoxidation procedure. In the field of nutrition much attention is being given to the production of fish flour in a form suitable for enriching bread, and to its nutritional evaluation. Investigation of pentachlorophenol and other substances as inhibitors of corrosion of concrete by sulphuric acid - producing bacteria indicated that use of bactericidal cements is unlikely to prevent corrosion of concrete sewers in warm climates and that the solution must be sought in designing the sewer so as to prevent the build-up of hydrogen sulphide concentrations. The surface diffusion of adsorbed molecules has been further investigated and also the uptake of the systemic insecticide, $\mathrm{OO}^{\prime}$-diethyl o-ethylmercaptoethyl thiophosphate, from the point of view of its possible toxicity for human consumption.

The National Physical Laboratory is also experiencing difficulties in recruiting staff, particularly nuclear physicists and biophysicists, from abroad. Satisfactory progress is reported, however, with the erection of the cyclotron, which should have been complete by December 1955. Assistance is being rendered on an increasing scale to the Geological Unit of the Atomic Energy Board. A new method, based on an exchange reaction using radioactive iodine es tracer element, is being investigated for determining thyroid hormone in the blood, and the first phase of a study of hookworm infestation with iron-59 as tracer has been concluded. Progress is reported in the construction of a highly sensitive mass-spectrometer for the analysis of age of minerals with low uranium content, and electron-microscope observations on grain boundaries, sub-grain boundaries and slip traces on aluminium-copper alloys have provided direct evidence of the presence of dislocations. X-ray diffraction studies show that nickel, cobalt and zine acetates have normal structures unrelated to those determined for cupric and chromous acetates. A curved crystal monochromator has been designed and built for the study of plastic deformation in metals, and a photometric method has been developed for the determination of sodium, potassium and calcium and also methods for determining the trace elements cobalt, molybdenum, zinc, lead, vanadium, chromium, nickel and sulphur. Further work has been done towards the establishment of primary temperature standards, and a new building for acoustic research completed and occupied. Electronic circuits for a 
direct-reading spectrograph have been designed so as to eliminate the photographic plate and thus speed up spectrochemical analysis.

Considerable progress has been made in establishing facilities for research in mechanical engineering. An investigation on the influence of predeformation on the plastic properties of metals continued, and a fundamental investigation was commenced into the effect of interrupted loading and periodic overloading on the fatigue of metals. Considerable progress was made with the construction of apparatus for examining the use of South African coal as gas-turbine fuel and for the study of heat transfer between solid boundaries and fluids, while equipment has been designed for the study of heat transfer under condensing conditions. Facilities are also being developed for testing and calibrating instruments to measure accurately the low air-speeds which often prevail in ventilated spaces, and a study of fan design in relation to noise has been started.

The work of the Telecommunications Research Laboratory has included the measurement of radio noise-levels at $100 \mathrm{kc} . / \mathrm{s}$. with the view of assessing the effect of atmospheric radio noise on navigational aids, the study of the occurrence of precipitation static and corona effects in aircraft in flight, a survey of the effect of soil and terrain on the propagation of lowfrequency radio waves in South Africa, and the study by radar of lightning discharges, while for the Department of Defence radar equipment specially suited to South African conditions is being developed. The National Building Research Institute has occupied its new Building Research Laboratory; although the move considerably interrupted laboratory work, fundamental work was carried out on foundations on expansive clay soils and on the behaviour of the hydration products of cement minerals in aggressive solutions ; a brochure of house plans for the urban Bantu was prepared as well as a guide to the planning of Bantu primary schools and a paper of climatic data for use in the design of buildings in the Union.

The work of the National Institute for Personnel Research has been handicapped by a shortage of graduate staff and a labour turnover as high as 27 per cent. Considerable work continues to be done on personnel selection, although the work generally is now directed to the efficient use of personnel, including aptitude tests for native labour, field studies of the mentality of indigenous African peoples, and studies on the nature and measurement of personality and of the forensic and sociological implications of electroencephalography. Defence research included a study of methods of assessing flying proficiency and a new general screening and classification test for the Union Defence Forces. Besides collecting data on road accidents in a large passenger transport corporation, the Institute is investigating the causes of motor-cycle accidents.

The Leather Industries Research Institute records progress in its studies on the structure and molecular weight of wattle tannin fractions, the structure of the chromium complex, the theories of vegetable and chrome tannage, the physical properties of the globular proteins of hides and the shape characteristics of various South African groups of feet. Much of the work of the Fishing Industry Research Institute was again on a short-term basis, but it included attempts to discover a satisfactory objective test for freshness and to determine nutritional values and trace elements in marine products. The Sugar Milling
Research Institute continued to study methods of juice clarification, and much attention was paid to the oceurrence of starch in cane juice and in sugars. The Paint Industries Research Institute's examination of paint performance has indicated that the climate in Durban is exceptionally severe, and that the simpler kinds of finish do not give good results. The most notable achievement of the South African Wool Textile Research Institute has been the development of a theory of the origin of medium-and longterm irregularity in worsted yarn which permits detection of a machine that is not drawing properly and also forecasts the minimum number of drawing operations required to draw and spin a given wool top. The Bituminous Binder Research Unit has completed a preliminary investigation of photooxidation in the weathering of binders on the road and is attempting to establish the physical mechanism of binder failure under traffic. Medical research has included further work on the culture of amoba, the pathology of bilharziasis in experimental animals, the serological diagnosis of cercariæ, the use of the ballistocardiogram in assessing the functioning of the heart, studies in the nutrition of Bantu infants and young children, the macromolecular syndrome and the experimental physiology and motabolism of the baboon, physico-chemical studies on animal viruses, and studies on bacteriophage inhibitors and the isolation of viruses.

\section{TECHNICAL CO-OPERATION SCHEME OF THE COLOMBO PLAN}

TN June 1955 the Technical Co-operation Scheme of 1 the Colombo Plan, the main purpose of which is to help member countries to raise the level of tech. nical skills among agricultural, industrial and other workers, in co-operation with the technical assistance programmes of the United States and of the United Nations and its Specialized Agencies, completed its fifth year, and the report for 1954-55*, issued by the Council for Technical Co-operation in South and South-East Asia, records that all four main developments noted last year gathered momentum.

There was an increased flow of technical aid experts, trainees and equipment: 1,023 training places were provided in 1954-55, compared with 508 in 1953-54, bringing the total to 2,676 , of which 440 were for training in agriculture, 428 in administration, 331 in engineering, 305 in education, 293 in medicine and health, 219 in industry and trade, 195 in transport and communications and 146 in power and fuel. Australia took 916 trainees, Great Britain 853, India 340, Canada 311 and Now Zealand 226. The demand for experts, 129 of whom were provided in 1954-55 (compared with 86 in 1953-54), making a total of 392 against applications for 672 , was heaviest in medicine and health (117), with transport and communications (54), engineering (51), food, agriculture and forestry (47), education (42) and industry and trade (27) following. Great Britain provided 157 experts, of whom 65 went to Ceylon, 64 to India and 23 to Pakistan; Australia 115 (35 to Malaya, 28 to Ceylon, 28 to Pakistan), Canada 59 (26 to Ceylon, 11 to Pakistan); New

* Colombo Plan. Technical Co-operation Scherre. Report for 1954Asia. (London : H.M.S.O., 1955.) 18. 3d. net. 